\title{
Green auctions versus flat rate agri-environmental payments
}

\author{
Andrea Cattaneo ${ }^{1)}$, Jussi Lankoski ${ }^{2}$ and Markku Ollikainen ${ }^{3)}$ \\ ${ }^{1)}$ OECD, Trade and Agriculture Directorate, 2, rue André-Pascal 75775 Paris CEDEX 16, \\ andrea.cattaneo@oecd.org. \\ ${ }^{2)}$ OECD, Trade and Agriculture Directorate, 2, rue André-Pascal 75775 Paris CEDEX 16, \\ jussi.lankoski@oecd.org. \\ ${ }^{3}$ University of Helsinki, Department of Economics and Management,P.O. Box 27, FIN-00014, University of \\ Helsinki,markku.ollikainen@oecd.org.
}

\begin{abstract}
This study examines how jointness of environmental benefits and environmental heterogeneity affect auction designs and the potential benefits of green auctions over conventional flat rate agri-environmental policies. A sealed bid green auction is used to promote an agri-environmental program with two environmental targets, nutrient runoff reduction and biodiversity provision. A score index comprising of environmental performance and the monetary size of bid is developed to rank the farmers' applications. The green auction is analyzed empirically by using Finnish data.

An auction that screens according to the environmental score and another one with an additional cost-saving component are simulated in the context of two different conservation options based on whether enlarged field edges are located in whichever edge of a parcel, providing only biodiversity benefits or are located on the waterfront (buffer strip) providing joint benefits in terms of promoting biodiversity and reducing nitrogen runoff. Empirical results show that independently of whether the auction program supports simple enlargement of field edges or buffer strips, the green auction with the cost saving component has the highest social welfare performance, followed by the flat rate payment, followed in turn by the green auction ranking by environmental score. When environmental benefits are jointly produced by an environmental practice the social welfare dominance of the green auction with cost-saving is further enhanced.
\end{abstract}

Keywords. Green auction, bid, joint environmental benefits, score index value 


\section{Introduction}

Most agri-environmental programs in Europe are based on fixed flat rate payments provided to farmers who comply with a predetermined set of management practices/criteria, such as reduced tillage or limits on the intensity and timing of fertilizer, manure and pesticide applications. The obvious problem with this type of flat rate payment approach is that heterogeneity in neither farmers' compliance costs nor site-productivity of environmental goods supplied are taken into account in policy design and implementation.

Designing and implementing more efficient agri-environmental policies is difficult because of asymmetric information between a farmer and a policy maker (Latacz-Lohmann 2004). Information asymmetries exist if farmers have hidden information (or characteristic), which may lead to adverse selection, or alternatively, hidden action, which may give rise to moral hazard. Informational asymmetries are due to the inability of policy maker to produce exact knowledge for policy designs or to carry out effective monitoring activities. Principal-agent models are typically used to address the adverse selection problem in agriculture (e.g. Wu and Babcock 1996 and Moxey et al. 1999). Enforcement models address the problem of agricultural moral hazard (Choe and Fraser 1998, 1999, Ozanne et al. 2001, White 2002, and Fraser 2002).

Auction theory provides an interesting way to extend the principal-agent approach by incorporating competition between agents for winning a contract with the principal. Auctions have been recently applied to environmental conservation on agriculture (Latacz-Lohmann and Hamsvoort 1997, Stoneham et al. 2003, Vukina et al. 2006). In conservation auctions, farmers bid competitively for a limited amount of environmental conservation contracts. When making a bid a farmer faces a trade-off between net payoffs and acceptance probability so that a higher bid increases the net payoff but reduces the probability of getting a bid accepted. Thus, competitive bidding will push farmers to reveal their compliance costs and as a result it will reduce farmers' information rents and improve the cost-effectiveness of an agrienvironmental program.

Previous auction theory applications have not been very explicit in two important features affecting agri-environmental programs. First, environmental sensitiveness may greatly differ across the fields. For nutrient runoff into surface waters, the slopes of the field parcels towards a watercourse may be far more important than the actual fertilizer intensity. Accounting for this feature may crucially affect the results of bids in an auction but it has not been explicitly analyzed (see however, Vukina et al. 2006). Second, agrienvironmental programs provide benefits in multiple environmental dimensions. For instance, if the goal is to promote biodiversity by increasing the width of field margins also nutrient and pesticide runoff to waterways may be reduced jointly. The implications of jointness between multiple environmental outputs on auction design and outcomes have not been examined so far.

In this study we examine to what extent jointness and environmental heterogeneity affect the performance of different auction designs vis-à-vis conventional flat rate policies. The study aims to determine whether the possibility of exploiting practices that provide multiple environmental benefits has an impact on the relative performance of different policy designs. We specifically focus on an agrienvironmental program that promotes two environmental targets, nutrient runoff reduction and biodiversity provision. For the auction specification we apply an environmental index to unify the aspects of environmental benefits. By giving weights to different environmental aspects in the program, the index establishes the relations between these aspects as concerns their relative priority. We use a score index to rank the farmers' applications. The score index is a product of two aspects: environmental performance and the monetary size of the bid. Both the environmental and the score index are common knowledge helping the farmers to assess how their deliberate actions affect their chances of getting their bids accepted.

We investigate auctions both analytically and empirically by using Finnish data. We compare a flat rate policy with two alternative auction designs, a green auction without and with a cost saving component. We start with the case in which environmental benefits are disjoint and compare the green auction's outcome to the socially optimal solution and flat rate policy giving special emphasis on environmental heterogeneity. 


\section{Empirical model}

We assume that environmental performance includes two components: an improvement in agricultural biodiversity (BD) and in water quality by reducing nutrient runoff (BZ). In working lands (cultivated lands), biodiversity is mostly promoted by field margins, which provide semi-natural habitat for wildlife. Reducing nutrient runoff can be made by many means. The most obvious way is to reduce fertilizer application, another is provided by establishing buffer strips between fields and waterways.

The empirical model contains 40 differential land productivities. Environmental heterogeneity is introduced by letting each land productivity to have four different field slopes towards a watercourse. The size of each parcel is normalized to be one hectare; the total land area is 160 hectares distributed equally in the four slope categories. Land can be allocated to three alternative uses: forestry, crop 1 (rape) and crop 2 (spring wheat). The basic empirical model, including nitrogen response function, nitrogen runoff function and species-richness curve, has been described in detail in Lankoski and Ollikainen (2003) and Ollikainen and Lankoski (2005). Therefore, the focus here is to show basic features of green auctions.

Farmer's expected profits from the bid can be expressed as

$$
E \pi \equiv \Pi=\left[\pi_{1}(l, m)-\pi_{0}^{*}+r(l, m)\right] F(I) .
$$

Where $\pi_{0}^{*}$ is farmer's profit under privately optimal solution and $\pi_{1}(l, m)$ refers to profits under agri-environmental payment program, and $r(l, m)$ refers to farmer's bid (required payment). The economic problem of the farmer is to choose fertilizer use $l$ and buffer strip size $m$ (and thereby the bid $r$ ) so as to maximize the expected profits (1) from the bid subject to (1) and the constraints $E(l, m) \leq 1$ and $r \leq R$.

In the green auctions, the social planner maximizes the environmental goal of the agrienvironmental program subject to the requirement that payments for the accepted bids do not exceed the budget constraint $(\bar{G})$ of the program, defined by $\sum R=a^{*} I \leq \bar{G}$, where $a$ indicates how the maximum payment increases with environmental performance. As for the target function, the environmental performance index is a weighted linear average of nitrogen runoff reduction and biodiversity promotion. The weights are estimated using the actual social valuation of nitrogen runoff damages and biodiversity benefits in Finland. Estimation yields the weight 0.43 for biodiversity and 0.57 for runoff reduction. Thus, the environmental index, $E$, and the target function of the green auction ranking the bids according to their environmental performance (EnvMax), is given by,

$$
E=0.43 B D+0.57 B Z \quad(\text { EnvMax })
$$

When the cost saving component is added then the relative share of weights for biodiversity and runoff reduction is kept constant. We assign values in equation (1) by setting weights $\omega_{e}=0.6$ and $\omega_{r}=0.4$ to environmental performance and the cost-saving component to be associated with the bid, respectively. Thus, the target function with the cost saving component (CostSave), is

$$
I=\left[0.6 E+0.4\left(1-\frac{r}{R(E)}\right)\right] \bar{I} \quad \text { (CostSave) }
$$

\section{Policy simulations and results}

The empirical model is used to estimate the outcome of our EnvMax and CostSave green auction designs, which are compared with a flat rate payment approach that is currently implemented in Finland. To examine the role of jointness in a sharp focus we assume in both auctions that the enlarged field edges provide (a) biodiversity benefits only (disjoint benefits), or (b) biodiversity benefits and nitrogen runoff reduction (joint benefits). The agronomic requirement for joint benefits in field edges is that they are 
established between the fields and the water ways, and thereby called buffer strips.

Green auctions are compared with the current Finnish agri-environmental payment program that provides a flat rate payment to participating farmers as a compensation for the forgone profits of establishing 3 meter wide buffer strips. All policy options are compared with benchmark cases of the private (entailing no enlarged field edges), and the social optimum (with the full set of conservation options). Thus, the alternative policies are defined as follows:

1. Current flat rate agri-environmental payment (Flat rate): A uniform 3-meter wide enlarged field edge is required. The uniform agri-environmental payment as a compensation for forgone profits amounts to $€ 21 /$ ha. "Flat rate disjoint" and "Flat rate joint" refer to the disjoint and joint benefits, respectively.

2. Green auction ranking by environmental score (EnvMax): The bids are selected according to their environmental score. The private optimum is used as a reference to calculate the benefits from nitrogen use reduction. The budget is assumed to be restricted to the amount of the current flat rate payment approach described above. EnvMax_disj and EnvMax_joint refer to the auction disjoint and joint benefits, respectively.

3. Green auction ranking by environmental score and cost-saving component (CostSave): The bids are selected according to their environmental score and cost-saving component, which is given a weight 0.4. The private optimum is used as a reference to calculate the benefits from nitrogen use reduction. The budget is assumed to be restricted to the amount of the current flat rate payment approach. CostSave_disj and CostSave_joint refer to the disjoint and joint benefits, respectively.

Table 1 represents the overall social welfare, its components and accepted/rejected bids in the auctions. Social welfare includes the social cost of public funds (marginal excess tax burden) for which we use $15 \%$ as the estimate. In the flat rate payment program, the environmental payment is set at level $€ 21$ per ha and the overall agri-environmental budget for green auctions is defined by the budget in the flat rate payment (€ 2482).

Table 1. Disjoint benefits: social welfare performance of alternative policies.

\begin{tabular}{ccccccc}
\hline Policy & $\begin{array}{c}\text { Profits, } \\
\boldsymbol{\epsilon}\end{array}$ & $\begin{array}{c}\text { Budget } \\
\text { outlays, } \\
\boldsymbol{\epsilon}\end{array}$ & $\begin{array}{c}\text { Accepted/ } \\
\text { rejected } \\
\text { bids, } \#\end{array}$ & $\begin{array}{c}\text { Runoff } \\
\text { damage, } \\
\boldsymbol{\epsilon}\end{array}$ & $\begin{array}{c}\text { Biodiversity } \\
\text { benefits, } \\
\boldsymbol{\epsilon}\end{array}$ & $\begin{array}{c}\text { Social } \\
\text { welfare, } \\
\boldsymbol{\epsilon}\end{array}$ \\
\hline $\begin{array}{c}\text { Private } \\
\text { optimum }\end{array}$ & 11422 & - & - & 5695 & 1288 & 7617 \\
$\begin{array}{c}\text { Social } \\
\text { optimum }\end{array}$ & 10216 & - & - & 2622 & 3348 & 11615 \\
$\begin{array}{c}\text { Flat rate } \\
\text { disjoint }\end{array}$ & 13001 & 2482 & - & 6893 & 4223 & 8203 \\
$\begin{array}{c}\text { Green auction: } \\
\text { EnvMax_disj }\end{array}$ & 11458 & 955 & $13 / 13$ & 5297 & 1649 & 7458 \\
$\begin{array}{c}\text { Green auction: } \\
\text { CostSave_disj }\end{array}$ & 11578 & 874 & $92 / 92$ & 5083 & 2927 & 9151 \\
& & & & & &
\end{tabular}

By definition, welfare in all policies remains below the socially optimal solution. The green auction with cost saving performs best and is followed by the flat rate policy and then the auction ranking the bids by their environmental score (EnvMax_disj). The budget outlays for both auction designs are considerably lower than the budget constraint imposed by the equivalency with the flat rate payment program, because all applicants are accepted without exhausting the funds.

The fact that the budget is not exhausted highlights two potential problems when designing an auction mechanism: either there are too few applicants or if there many, the majority of bids can be characterized as "low-cost-low-quality". Both are linked to the relationship between how points are 
assigned and farmers' expectations about what is an "acceptable" score (for which a bid has a reasonable chance of being accepted). In the pure environmental ranking auction the costs of attaining what is perceived as an accaeptable score are too high for most farmers and less than $15 \%$ of eligible plots (those in crops) are bid into the program. The outcome is, in social welfare terms, worse than the private optimum.

When the cost-saving component is included in the ranking it becomes considerably easier to attain what is perceived as an acceptable score, as is highlighted by $100 \%$ participation among parcels in crops. The farmers' strategy in this case is to provide relatively small environmental improvements and requesting low payments. Fertiliser intensity is reduced for rape, but only very little for wheat, and buffers are much smaller than socially optimal. Despite these shortcomings the social welfare outcome for the green auction with the cost-saving component is significantly higher than both the private optimum and flat rate payment policy. The tentative policy implication from these results is that it is better to err on the side of inclusiveness, by incorporating a cost-saving component in the ranking mechanism, than to have a program with high ambitions in terms of environmental performance at the risk of having few applicants.

We next analyze the case where the environmental benefits provided by enlarged field edges (now buffer strips) are joint. Table 2 compares the social welfare performance of alternative policies relative to the private and social optima. All three policies are welfare-enhancing relative to the private optimum; however, their performance differs substantially in terms of aggregate welfare and environmental performance. The green auction with the cost-saving component (CostSave_joint) dominates other policy designs. It induces the highest welfare and brings runoff damages and biodiversity benefits close to the optimum. As in the previous section, the flat rate payment policy outperforms the auction that maximizes the environmental score (EnvMax_joint). Accounting for the jointness in fact increases the advantage of the flat rate policy. Interestingly, the advantage of the flat rate policy is obtained by counterbalancing the high runoff damages with the over-provision of biodiversity benefits.

Table 2. Joint benefits: social welfare performance of alternative policies.

\begin{tabular}{ccccccc}
\hline Policy & $\begin{array}{c}\text { Profits, } \\
\boldsymbol{\epsilon}\end{array}$ & $\begin{array}{c}\text { Budget } \\
\text { outlays, } \\
\boldsymbol{\epsilon}\end{array}$ & $\begin{array}{c}\text { Accepted/ } \\
\text { rejected } \\
\text { bids, \# }\end{array}$ & $\begin{array}{c}\text { Runoff } \\
\text { damage, } \\
\boldsymbol{\epsilon}\end{array}$ & $\begin{array}{c}\text { Biodiversity } \\
\text { benefits, } \\
\boldsymbol{\epsilon}\end{array}$ & $\begin{array}{c}\text { Social } \\
\text { welfare, } \\
\boldsymbol{\epsilon}\end{array}$ \\
\hline $\begin{array}{c}\text { Private optimum } \\
\text { Social optimum } \\
\text { Flat rate joint }\end{array}$ & 11422 & - & - & 5695 & 1288 & 7617 \\
$\begin{array}{c}\text { Green auction: } \\
\text { EnvMax_joint }\end{array}$ & 130016 & - & - & 2622 & 3348 & 11615 \\
$\begin{array}{c}\text { Green auction: } \\
\text { CostSave_joint }\end{array}$ & 12448 & 2515 & $24 / 68$ & 4215 & 2051 & 8370 \\
& 12369 & 2484 & $58 / 34$ & 3292 & 2932 & 10127
\end{tabular}

The presence of jointness in environmental benefits changes the number of bids submitted and accepted in the two auctions. Recall, under disjoint benefits we had less than $15 \%$ of all plots in crops submitted as a bid when applications were ranked by environmental score whereas with joint benefits this number increases to $100 \%$. Jointness implies that the environmental benefits from a unit of buffer are higher and it is easier for the farmer to construct a bid with an acceptable score. Whilst previously all bids were accepted, in the joint benefit case only $25 \%$ of submitted bids are accepted.

Relative to the environmental ranking with joint benefits, the ratio of accepted bids improves when the cost-saving component is incorporated in the ranking, going up to $63 \%$. It is interesting to note that, relative to the case with disjoint benefits, fewer bids are accepted when benefits are joint. This is because on the demand side, since jointness implies higher environmental benefits from a unit of buffer, the agency will be willing to "retire" more productive land into buffer, and farmers are happy to bid that land into the program up to their opportunity cost. Therefore, the cost of bids is higher when benefits are joint. Welfare is enhanced because the greater reduction in runoff damage and improvement in biodiversity compensate for higher unit costs of conservation. Cost saving clearly matters, as acceptance rate is much higher under the cost-saving auction than the case without factoring in costs, leading to a better outcome in social welfare terms. 


\section{Conclusions}

This study analyzed to what extent jointness and environmental heterogeneity affect the performance of different auction designs vis-à-vis conventional flat rate policies. We compared a flat rate policy to a green auction without and with a cost saving component assuming that environmental benefits were either disjoint or joint. For the auctions a score index was developed to rank the farmers' applications.

Both joint and disjoint benefits result in the same ranking of policies. The green auction with the cost saving component outperforms others. For joint benefits the outcome is quite close to the social optimum. In contrast, the green auction ranking by environmental score performed worse, and was even less welfare-enhancing than the flat rate payment. This demonstrates the importance of the cost-saving component in environmental policy design. Ranking the bids exclusively by their environmental score creates incentives to over-provide environmental benefits for a fixed payment to increase their chances of acceptance.

Jointness of environmental benefits plays an important role for the performance of the green auctions. Allowing for joint benefits made both auctions (also the flat rate policy) more successful, because the costs of providing environmental benefits were reduced. More importantly, the auctions with disjoint benefits are much more sensitive to how objectives and cost-saving are weighted leading to swings in participation. When maximizing the environmental score too few bids are submitted, whereas when costsaving is incorporated there are many applicants but the majority of bids are "low-cost-low-quality". The potential uncertainty in farmer response to program design can be a considerable drawback of a program with conservation practices that do not provide benefits jointly.

\section{References}

Choe, C. and Fraser, I. (1998). A note on the imperfect monitoring of agri-environmental policy. Journal of Agricultural Economics 49(2): 250-258.

Choe, C. and Fraser, I. (1999). Compliance monitoring and agri-environmental policy. Journal of Agricultural Economics 50(3): 468-487.

Fraser, R. (2002). Moral hazard and risk management in agri-environmental policy. Journal of Agricultural Economics 53(3): 475-487.

Lankoski, J. and Ollikainen, M. (2003). Agri-environmental externalities: a framework for designing targeted policies. European Review of Agricultural Economics 30: 51-75.

Latacz-Lohmann, U. (2004). Dealing with limited information in designing and evaluating agrienvironmental policy. $90^{\text {th }}$ European Seminar of the European Association of Agricultural Economists "Multifunctional agriculture, policies, and markets: understanding the critical linkages", Rennes, France, 28-29 October, 2004.

Latacz-Lohmann, U. and C. Van der Hamsvoort (1998)"Auctions as a Means of Creating a Market for Public Goods from Agriculture," Journal of Agricultural Economics, 49(3):334-45

Latacz-Lohmann, U. and C.P.C.M. van der Hamsvoort (1997): Auctioning conservation contracts: a theoretical analysis and an application. American Journal of Agricultural Economics 79 (2): 407-418.

Moxey, A., White, B. and A. Ozanne (1999). Efficient contract design for agrienvironmental policy. Journal of Agricultural Economics 50(2): 187-202.

Ollikainen, M. and Lankoski, J. (2005). Multifunctional agriculture: the effect of non-public goods on 
socially optimal policies. MTT Discussion Papers 1. 2005.

Ozanne, A., Hogan, T. and Colman, D. (2001). Moral hazard, risk-aversion and compliance monitoring in agri-environmental policy. European Review of Agricultural Economics 28(3): 329-347.

Stoneham, G., Chaudhri, V., Ha, A. and Strappazzon, L. (2003). Auctions for conservation contracts: an empirical examination of Victoria's Bush Tender trial. Australian Journal of Agricultural and Resource Economics 47(4): 477-500.

Vukina, T., Levy, A. and Marra, M. (2006) "Do Farmers Value the Environment?

Evidence from the Conservation Reserve Program Auctions", Contributed paper, International Association of Agricultural Economists - 2006, Brisbane, Australia.

White, B. (2002). Designing voluntary agri-environmental policy with hidden information and hidden action: A note. Journal of Agricultural Economics 53(2): 353-360.

Wu, J. and Babcock, B.A. (1996). Contract design for the purchase of environmental goods from agriculture. American Journal of Agricultural Economics 78: 935-945. 